Simone Perelson

Universidade Federal do Rio de Janeiro

\title{
A parentalidade homossexual: uma exposição do debate psicanalítico no cenário francês atual
}

\begin{abstract}
Resumo: Após situar a homoparentalida de no contexto das novas práticas sociais e médicas referentes à filiação e à reprodução, o artigo apresenta um cenário do debate francês atual sobre essa questão. Serão nele confronta dos os pensa mentos de c inco psic a na lista s: J oël Dor, e sua teorização sobre o papel da função paterna e da diferença ana tômic a entre os sexosna estruturação do sujeito; Pierre Legendre, e sua articulação entre os campos do jurídico e do psíquic o na inscrição do ser humano na ordem da filiação; Michel Tort, e sua crítica às teorias de Legendre; Geneviève Delaisi de Parseval, e sua proposta de uma definição mais a mpla da família; e, enfim, Sabine Prokhoris, e a sua distinção entre 'sexuação' e 'diferença dos sexos'. Através dessa a presentação, buscar-se-á desmontar os argumentos contrários e indicar a legitimida de da argumentação fa vorável à filiação homossexual.
\end{abstract}

Palavras-chave: homoparentalida de; reprodução; filiação.

Copyright $\propto 2006$ by Revista Estudos Feministas.

${ }^{1}$ Os neologismos mono, multi e homoparentais são criados a partir da palavra de origem anglófona "parentalidade"(parenthood), que se generalizou a partir de 1970 para definir o pai ou a mãe segundo sua faculdade de alcançar uma função dita parental. 0 temo monoparentalidade indica, portanto, o exercício dessa função porum único a dulto (pai ou mãe) - caso das chamadas "produções independentes" -, o termo multiparentalidade indica a prática desse

\section{A relação entre as novas práticas socia is no campo da família e as novas práticas médicas no campo da reprodução}

Atualmente experimentamos não apenas a generalização de formas de família a té há pouco tempo raras ou marginalizadas, como também o surgimento de formas de filiação que mesmo hoje nos parecem de difícil rep resenta çã o, nos sentid os p síquic o, soc ial, étic o e juńdico. Essa snova s fo rmas de fa mília são um efeito tanto dasnovas práticas sociais no campo da família - famílias monoparentais, multiparenta is e homoparenta is ${ }^{1}-$ como $^{2}$ ta mbém das novas práticas médicas no campo da reprodução - insemina ção artificial ho móloga (com sêmen do próprio cônjuge ou companheiro) e heteróloga (com 
exercício por vários adultos - o que é bastante comum em casos de famílias recompostas -, e o termo homoparentalidade designa a situação familial na qual pelo menos um dos pais se assume como homossexual (cf. Martine GROSS, 2000), podendo essa situação decorrer tanto da recomposição de fa míliasquanto da adoção ou da reprodução assistida. Como observa Flá vio Luiz TARNOVSKI, 2002, esse termo é introduzido na França pela Association des Parents et Futurs Parents Gays et Lesbiennes e o caráter distintivo que ele parece assina la ré justamente a possibilidade de articulação entre as experiências da parentalidade e da homossexualidade que, pelo menos do ponto de vista dos sujeitos, deixam de serconflitivas. A respeito do termo parentalidade e dos neologismos criados a partir dele, ver Esther GOODY, 1982. A respeito do debate acadêmico e político sobre homoparentalidade no Brasil, ver, a lém de TARNOVSKI, 2002, Miria m GROSSI, 2003, e Anna Paula UZEL, 2002 e 2004.

${ }^{2}$ A respeito das várias técnicas médicasde reprodução assistida, ver Marilena CORREA, 2001.

${ }^{3} \mathrm{Cf}$. Geneviève DELAISI e Pierre VERDIER, 1994, p. 53

${ }^{4}$ BRAUNER, 2004, p. 7. A respeito da vá rias discussões jurídic as provocadas pelas novas tecnologias reprodutivas, ver Débora DINIZ e Samantha BUGLIONE, 2002.

5 TORT, 1992.

${ }^{6} \mathrm{C}$ abe observarque a disc ussã o a respeito do caráter inédito ou não das filiações via biliza das pelasnovas tec nologias reprodutivas vai dividir os teóricos da a ntropologia, enquanto, como nos mostra Marlene TAMANINI, 2004, uma autora como Simone BATEMAN, 2001, sublinha o fato de que essa tecnologia necessariamente coloca em causa 0 modelo de referência em matéria de conduta procriativa, a saber, a relação sexual entre um homem e uma mulher, modelo que remete a o que parece sera doação de sêmen), FIV (podendo esta sercom doação de sêmen, óvulo ou embrião), prátic a de útero de substituição e clonagem humana. ${ }^{2}$

Para tentar abordar essas novas formas de família, é necessário compreendermos o elo ou, a inda, a relação dialética entre as acima referidas novas prátic as médicas e as novas práticas sociais, isto é, entre as evoluções científicas e as transformações socia is nos campos da reprodução e da filiação. Se nos anos 60 , anos da revolução sexual, a contracepção generaliza da - que ao mesmo tempo viabilizava essa revolução e era por ela viabilizada - colocava em cena, como reivindicação e como realidade, o sexo fora da reprodução; a partir dos anos 80 , com os progressos no campo das novas tecnologias reprodutivas, reivindica-se e realiza-se a reprodução fora do sexo. ${ }^{3}$

A reprodução via tecnologia, a o separar sexo e reprodução, irá também separar mães e pais biológicos, por um lado, e mães e pa is sociais, por outro. Além disso, trará inúmeras questões tais como: quem é a mãe no caso de doação de óvulo ou de útero de substituição?; quem é o pai no caso de doação de sêmen?; qual o direito que tem a criança de saber quem são os seus pa is biológicos?; qual a importância, para a criança, dos pais biológicos?; qual a relação entre pais biológicos e pais socia is?; como se monta, enfim, a filiação? Além disso, a o desa rtic ula r sexo e reprodução, ou a inda reprodução e filia ção, a o via biliza r, por exemplo, a maternidade para mulheres em menopausa, virgens ou a té mesmo nunca nascidas (neste último caso, pela maturação de ovócitos de fetos não viá veis), ou ainda, a patemidade para homens mortos (por fecundação do sêmen congelado), as novas tecnologias reprodutivas desvinculam a matemidade e a patemidade, como observa a jurista Maria Claudia Bra uner, ${ }^{4}$ dos limites e imposições traçados pela tradição e pela biologia humana. Ou ainda, como nos mostra rá o psicanalista Michel Tort, ${ }^{5}$ elas nos convidam a repensar a ordem simbólica de nossas genealogias. ${ }^{6}$

Não devemos, entretanto, compreender aqui a relação entre evoluçõescientífic ase transforma ções sociais como uma simples rela ção de causalida de. Como observa Michel Tort, se as novas técnicas médicas subvertem fund a menta Imente os nossos princípios id entitá riose exig em o estabelecimento de novas ordens simbólicas, essas mesmastéc nic as "rea lizam biologicamente, sob uma forma pa rticular, transformações das relações de parentesco e das formas de família que excedem completamente a procria ção a rtificial". 7 
ordem natural dascoisas. Débora DINIZ e Rosely GOMES COSTA, 2005. compreendem, a o contrário, a poiadas nas teorias sobre a procriação de Marilyn STRATHERN, 1992, que as tecnologias conceptivas replicam a reprodução natural, ou seja, conservam o modelo considerado natural de procriação. Entre essas duas posições, encontra-se a aguda observação de Françoise HÉRITIER-AUGÉ, 1985, para quem, embora possamos a firmar que as novas tec nologias conceptivas abalam o modelo da reprodução natural, elas não seriam as primeiras a fazê-lo. 0 que indica Heritier, como nos mostra Marcela IACUB, 1999, é que os sup ostos modelos inéditos colocados em cena pela medicina reprodutiva apenas reproduzem tecnicamente soluções já adotadas por algumassociedades tradiciona is. Sem entra mos no mérito dessa discussão, que julga mos pertinente aqui ao menos a presentar, seguiremos o nosso objetivo, a saber, indicar os efeitos perturbadores das novas tec nologias reprodutivas sobre a ordem procriativa fundada no que podemos chamar de uma "ficção do natural".

7 TORT, 1992, p. 53-54.

Esta e as demais citações de textos em francês são traduzidas pela autora.

${ }^{8}$ DELAISI DE PARSEVAL, 1999, $\mathrm{p}$. 240-241.

${ }^{9}$ DELAISI DE PARSEVAL, 1999, $p$. 242.

${ }^{10}$ Em 1999 é liberado, na França, o "Pac to Civil de Solidariedade", permitindo o que pode servulgarmente chamado de "casamento homossexual", sem incluir, entretanto, o direito à filiação por parte do casal.
A revelação da fragilidade e da contingência da ordem simbólica fundadora de nossas genealogias, revela ção essa via biliza da ta nto pelas nova s práticas socia is quanto pelas novas práticas médicas, mas sobretudo pelo elo entre ambas, é atualmente o que move as várias reivindicações ao direito do exercício de formas inéditas de patemidade e matemidade. Entre essas formas cabe destacar a dos casais homossexuais, tanto pelo seu vigor quanto pela resistência que provoca, seja no campo da sociedade, seja no campo teórico.

Como observa Geneviève Delaisi de Parseval, o questionamento atual sobre a homoparentalidade está relacionado a um abalo prévio das representações da maternidade e da patemidade, provocado em grande parte pelas diferentes técnicas de assistência médica à reprodução. Com efeito, a o desarticulara reprodução do coito fecundante, ao criar um despedaçamento da experiência reprodutiva e a o multiplicarosco-genitores ou c o-pa rentes, essa s téc nica s cria ra m situa ções inéd ita s, que "permitiram a consideração de demandas atípicas que contomam a sexualidade". ${ }^{8}$ A pergunta que então passa a ser colocada à sociedade pelos ca sa is homossexua is é: "com que direito vocês nos discriminam, nós, casa is fenomenologicamente estéreis, enquanto pa is potenciais; enquanto a sociedade aceita (e financia) as demandas dos casais estéreis com a condição que eles sejam heterossexuais?"9

Paradoxalmente, as técnicas que começaram a se desenvolver para fomecer aos casa is heterossexua is 'filhos naturais', mesmo que freqüentemente de modo absolutamente fictício (nos casos de doação de gametas ou embriões), e visand o à primeira vista a proteção de uma concepção tradicional da vida familiar, contribuíram em larga escala para formar novas exigências morais em matéria de procriação.

Associada a impacto moral e social das novas tec nologias reprodutivas, a liberação, em 1999, na França, do PACS $^{10}$ provocou nesse país um amplo debate acerca da legitimidade da filiação homossexual, debate do qual a psic a ná lise e os psic a na lista s fra nc eses vêm participando a tivamente. Buscaremos a qui a presentar minimamente 0 cenário desse debate, indicando seus principais pontos de confronto e discussã o.

\section{Um cenário do debate atual francês sobre a homoparentalidade}

Em 1992, em seu livro O desejo frio: procriação artificial e crise dos referenciais simbólicos, Michel Tort 
${ }^{11}$ TORT, 1992, p. 7.

12 TORT, 1992, p. 7.

\footnotetext{
${ }^{13}$ TORT, 1992, p. 7.

${ }^{14}$ TORT, 1992, p. 7.
}

${ }^{15}$ TORT, 1992, p. 12.

${ }^{16}$ TO RT, 1992, p. 12.

${ }^{17}$ TORT, 1992, p. 8. observa que, ao se confrontarem com os efeitos perturbadores causados pela medic ina da reprodução, políticos, médicos e cientistas humanos começam a recorrer, de forma bastante caricatural, ao discurso psicanalítico para sustentar duas posições radicalmente opostas. A psicanálise passa a ser, com efeito, convocada tanto pelo a rrogante discurso positivista liberal idealizador de todos os efeitos da ciência quanto pelo discurso moralizador e anticientific ista. No primeiro caso, a pela-se ao discurso psicanalítico buscando encontrar nele "um novo arsenal de argumentos para controlar as pulsões, impor limites ao indivíduo, num momento em que os 'sistemas simbólicos, especialmente religiosos, estão em crise no Ocidente". ${ }^{11}$ No segundo caso, o discurso psicana lítico, transforma do em discurso ideológico da liberação sexual, é convocado para afiançar "qualquer a tua ção coletivamente organizada pela biomedicina em nome do desejo". ${ }^{12}$

Como observa o autor, são sobretudo as diferenças de posição quanto à revelação da fragilidade e contingência do que rege atualmente as nossas genealogias, a saber, a ordem simbólica - ordem que vincula a filiação à diferença dos sexos e das gerações -, que ca rac terizam os deba tes franceses so bre as evoluções que levam a essas reivind ic ações. Esses deba tes colocam em cena, como observa Michel Tort, uma nítida oposição entre aqueles que consideram que "essas evoluções a meaçam as referências simbólicas fundamenta is da humanidade"13 e aqueles que "não vêem inconveniente algum em remanejar [essas referências] em função das possibilidades técnicas e das novas exigências". ${ }^{14}$ Como observa o psicanalista, criticando ambas as posições, os primeiros recorrem à psicanálise acreditando encontrar nela um discurso que Ihes permita salvar "o pai, a família, senão o trabalho e a pátria". ${ }^{15}$ Quanto aos segundos, 0 recurso à psicanálise é menor, mas, quando feito, o que buscam encontrar nela é uma caução "aos efeitos atomizantes do liberalismo". ${ }^{16}$

Recusando-se a adotar seja uma, seja a outra posição, Tort privilegia questionar "qual contribuição a psicanálise pode trazer à compreensão desse dispositivo novo que comanda as identificações através de um ordenamento inédito das funções matemas e patemas". ${ }^{17}$ $E$, para tal, afirma o autor, muito mais do que buscar na psic análise a caução ou a reprovação das novas práticas, é necessá rio efetua ruma reconsidera ção completa de suas certezas, sem perder, entreta nto, de vista a a rticula ção entre inconsciente, lei, sexualidade e corpo. 
${ }^{19}$ Segundo Tort, em meio ao debate sobre o PACS, a "homofobia psic analític a" se a presenta sob a foma de disc ursos denunciadores do "narcisismo pa tológ ico do homossexual, da "negação da diferença dos sexos", do "caráter arcaico e desviante da sexualidade homossexual" e do "perigo que os pais homossexua is fariam incorreràs crianças no que se refere ao seu equilíbrio psíquico e à constituição de sua identidade". Cf. TORT, 1999.

${ }^{20}$ ROUDINESC O, 2003.

${ }^{21}$ Intemational Psychoanalytical Association.
Em 1999, em meio a os calorosos debates, na mídia e na academia francesa, acerca da legitimidade da homoparentalidade provocados pela liberação do PACS Michel Tort retorna, em um artigo publicado em 15 de outubro no jomal Le Monde, ${ }^{18}$ ao tema do modo segundo o qual a psic análise é evoca da pelos vá rios sa beres dentro dos debates acerca das novas formas de parentesco e filia ção. O título do a rtigo - "Homofobias psicanalíticas" já indica que se trata de uma denúncia. E, com efeito, o que é denunciado no artigo é o lugar que a psicanálise passou a ocupar, dentro dos debates acima referidos, a saber, lugar de guardiã das boas condições de subjetivação, associando-se essas boas condições à manutenção de estruturas familia res calcadas na heterossexualidade dos pais. Portanto, se em 1992 a psicanálise parecia ora servir a o disc urso positivista liberal, ora a discurso anticientific ista normaliza dor, parece que em 1999, diante das questões colocadas pelo PACS, é princ ipa lmente do último disc urso que ela vai se a proxima r.

E caberá a Tort não a pena sindica rnão reconhecer nesse discurso normalizador proferido em nome da psicanálise a verdade da prática que ele próprio exerce, como também explicitar claramente a sua posição favorável à homoparentalidade e apontar as noções de 'ordem simbólica' - "estuário teóric o para onde confluem Lévi-Strauss, Lacan e o direito positivo da família" - e de 'função paterna' - que, junto com a primeira noção, constitui o "pivô da nova ordem familiar psicanalítica" como tendo um lugar determinante na passagem da psicanálise a um discurso normalizador de prescrição das condições da subjetivação. Deixando cla ro não objetivar disc utir as subtilida des do pensa mento la c a nia no a respeito dessas noções, Tort observa que o fato de a maior parte dos psic a na listas ditos la ca nia nos ter toma do uma posição francamente contrária à homoparentalidade nos debates sobre o PACS está intimamente relaciona do a o discurso sustenta do sobre os pilares dessas duas noções. ${ }^{19}$

A essa denúncia da homofobia psicana lític a calcada, como observará Tort, numa adaptação das posições da Igreja Católica à 'ordem simbólic a lacaniana', irá somar-se aquela que será empreendida, trêsa nos depois, porElisabeth Roudinesco, em seu livro A família em desordem. ${ }^{20}$ Vejamos em que termos se exprime a psicanalista:

Quando os casa is homossexua is franceses obtiveram em 1999 [...] um primeiro reconhec imento legal de sua vida comum, certos psic a na lista s la ca nia nos a d ota ram, assim como seus colegas da IPA, ${ }^{21}$ uma posição de especia listas. Sem nada conhecerem das experiências 
22 ROUDINESC O, 2003, p. 193.

${ }^{23}$ Cf. ROUDINESC O, 2003, p. 193.

${ }^{24}$ Cf. ROUDINESC O, 2003, p. 195.

25 Trata-se do livro Au-delà du PACS: L'expertise familiale à l'épreuve de I'homossexualité (Daniel BORILLO, Eric FASSIN e Marcela IACUB, 1999). Na revista Le Nouvel Observateur no 1859, de 22 a 28 de junho de 2000 , encontra-se publicado um interessante debate entre JeanPierre Winter e a psicanalista Sabine Prokhoris, em que são confrontados respectiva mente os argumentos contrários e favorá veisà homopa renta lidade. ${ }^{26}$ DOR, 1991.

${ }^{27}$ DOR, 1991.

${ }^{28}$ DOR, 1991, p. 14. americanas, lançaram-se em uma furiosa cruzada contra aqueles que acusavam de ser os adeptos de uma grande 'dessimbolização' da ordem social, ou a inda os responsá veis por uma nova tentativa de supressão da diferença sexual. ${ }^{22}$

Roudinesco, sem deixar de citar alguns dos vários psicanalistas franceses que teriam se imbuído dessa c ruza da - Gilbert Dia tkine, Césa r Botella, Jea n Pierre Winter, Simone Korfsa usse, Charles Melman ${ }^{23}$ e, sobretudo, Pierre Legendre -, deixa absolutamente clara a sua posição: a nossa sociedade, a firma a psicanalista, deve aceitar que os pais homossexua is existem e conceder-lhes os mesmos direitos concedidos a os pa is heterossexua is. ${ }^{24}$

J unto, a inda, a Michel Tort e Elisa beth Roudinesc o, e contra o grande rol de psicanalistas que vem vociferando contra os supostos perigos da homoparentalidade, cabe enfim citar as psicanalistas Sabine Prokhoris e Geneviève Delaisi de Parseval, cujos textos passaram a integrar uma das mais importantes publicações em que, a tra vés de artig os a ntropológicos, juríd ic os, so c iológic os, filosófic os e psicana líticos, várias fundamentações teóricas vieram responder critic amente aos discursos resistentes à constituição de casais e fa mílias homossexua is. ${ }^{25}$

Volta remos a essas duas autoras no final deste artigo. Por ora, buscaremos explicitar em que sentido os discursos psicanalíticos centrados nas noções de função patema e ordem simbólic a acabam por conduzir necessariamente a um discurso contrário à homoparentalidade. Para tal, apresentaremos, em primeiro lugar, uma teorização que, embora não se colocando explicitamente contra a filiação homossexual, não nos parece poder incluí-la como uma possibilidade. Trata-se a qui do pensa mento que o psic ana lista Joël Dor apresenta em seu livro o pai e sua função em psicanálise. ${ }^{26}$ Ao abordar o seu pensamento, buscaremos explicitar algumas das questões a que ele nos conduz. Em segundo lugar, apresentaremos o pensamento de Pierre Legendre, talvezo ma is reputa do e ferozautor de uma cruza da contra a homopa rentalidade. Talvezo seu ma ior mérito tenha sido o de provocar alguns psicanalistas, a tentos à s transforma ções históricas, a repensa rem, com a mesma fúria e deteminação, o edifício teónico da psicanálise.

Em seu livro sobre o pai e sua função em psic análise, J oël Dor ${ }^{27}$ demonstra em que sentido "nenhuma outra saída é proposta ao serfalante a não ser curvar-se ao que lhe é imposto poressa função simbólic a patema que o assujeita numa sexuação". ${ }^{28}$ A noção de pai, entidade universal essencialmente simbólic a e a-históric a, estrutura, com efeito, nosso ordenamento psíquico na qualidade de sujeitos. 0 pa i simbólico é o depositário legal da lei simbólica, isto é, 
${ }^{29}$ DOR, 1991, p. 57.

${ }^{30}$ DOR, 1991, p. 57.

${ }^{31}$ DOR, 1991, p. 58. a lei da proibição do incesto, e nesse sentido o seu lugar é o de um terceiro na lógica da estrutura, e ma is ainda de um terceiro a quem é a tribuíd o ima ginariamente o objeto fálico, suposto objeto do desejo da mãe.

Como observa Dor, visto que a dimensão do pai simbólic o transcende a contingência do homem real, não é necessário que haja um homem para que haja um pai. Basta que um terceiro, mediador do desejo da mãe e do filho, sustente esse lugar ou seja coloca do nesse lugarpelo discurso da mãe, indicando que o seu desejo (da mãe) se encontra ou se encontrou, a o menos dura nte certo tempo, a ele referido, para que seja significada sua função estruturante. Em outras palavras, o esta tuto do pai é de um puro referente, podendo ser da ordem de um significante - o Nome-do-Pai - cuja função simbólica é sustenta da pela a tribuição do objeto ima g iná rio fá lic 0 .

Entretanto, mesmo que o pai, enquanto pai simbólic o, possa ser reduzido a um signific ante no disc urso da mãe, sem nenhuma encama ção em uma figura real, e mesmo que a atribuição do falo a esse significante seja ima ginária, não é qua lquerfigura real que pode representálo, pois, como observa Dor, "a inda que se trate de lugares, isso não implica que os protagonistas sejam elementos situá veis indiferentemente entre eles". ${ }^{29}$ Ou seja, "um pai não pode ser uma mãe; da mesma forma, uma mãe não pode substituir um pai". ${ }^{30}$ Isso não está em contra dição, afirma o psicanalista, com o fa to de que uma mãe pode sempre identific ar-se com um pai, e vic e-versa. No primeiro caso, diría mosque uma mãe está em uma posição pa terna com relação a seu filho. Dor, então, observa que essa é a única ocorrência, aliás, em que é possível falar em mãe fálica. No segundo caso, o pai encontrar-se-ia em uma posição materna.

Assim, c onc lui o psic a na lista, "semelha ntes posições identific a tórias não têm o alcance simbólico que lhes é, respectivamente, a tribuído. No máximo, constituem parâmetros perturbadores e invalidantes quanto à demarc ação do falo pela criança em sua trajetória edipiana". ${ }^{31}$ Ou seja, uma mãe, mesmo que se situando em uma posição patema, não tem como ocupar o lugar da função patema, função à qual a criança deve submeterse para estruturar-se enquanto sujeito.

Pa ra explicara sua formulação, Dor a presenta na da ma is na da menos do que o exemplo de casa is de mulheres homossexua is que têm filhos. Porque, pergunta ele, em um c asal c omo esse, uma dasparceiras femininas nã o poderia ja ma is assumir a função pa tema, porma is que se esforç a sse para isso junto à criança? A resposta é simples e está liga da, a firma o autor, ao real, irredutível, da diferença entre os 
32 DOR, 1991, p. 58.

${ }^{33}$ DOR, 1991, p. 58-59. sexos. Como afirma Dor, "o papel matemo é inexpugnável, no sentido em que é instituído e sustentado pela questão da diferença dos sexos a os olhos da criança. Por sua vez, a função paterna só é operatória simbolicamente por proceder diretamente dela".32

Assim, não há função paterna sem que esta esteja referida a uma diferença sexual real com relação ao sexo da mãe. Citemos mais uma vez o a utor:

Certamente, basta que o signific ante Nome-do-Pai seja convocado pelo discurso matemo para que a função mediadora do Pai simbólico seja estruturante. Mas é nec essá rio a inda que este signific ante Nome-do-Pai seja explicitamente, e sem ambigüidades, referido à existência de um terceiro, marcado em sua diferença sexual rela tiva mente a o protagonista que se a presenta como mãe. É só nessas condições que, na ausência do pai real, o signific ante Nome-do-Pai pode ter todo o seu alcance simbólic $0 .{ }^{33}$

Em momento algum, o psicanalista afirma ser impossível o exercício da função paterna nos casos de mulheres homossexua is com filhos. Tampouco, ele sustenta ser isso possível. Ao buscarmos afirmar essa possibilidade, sem entra rmos em contra dição com o seu pensamento, poderíamos pensar na possibilidade de a função patema ser exercida nesses casos por um homem a quem o desejo da mãe esteja ou tenha, em algum momento, referido. Seguind o por essa via, entretanto, vá rias questões nos são colocadas. Em primeiro lugar, quem poderia ser esse homem: um homem que desejasse a mãe e que a mãe deseja sse? Mase se este não se a presentar, se o seu desejo sexual não estiver referido a homem algum? Um homem a quem a criança poderia supor estaro seu desejo referido? Mase se essa suposição ta mpouco se a presentar? Em última instância, o pai da mãe, a vô da criança? Mas aqui, mais do que a interdição do incesto, não seria a própria indistinção incestuosa que se colocaria em cena? Um a migo da mãe? Masaqui não está presente a questão do desejo sexual. Ou por exemplo, no caso das reproduções assistidas, o médico, terceiro termo a intervir no ato da fecundação, ou ainda o doador de sêmen, qua rto termo a intervir nesse ato? Essa poderia ser uma forma de pensarmos a função patema nos casos de reprodução a ssistida. Mas, a lém do fato de ela ser bastante questionável, não resolve todos os nossos problemas.

Não são poucos, de fato, os problemas colocados pela formulação teóric a que acabamos de descrever. Fora do quadro da triangulação papai-mamãe-criança, torna se deverascomplic a do sustentá-la. Essa dificulda de deriva, a nosso ver, da redução do que Dor chama aqui de real

716 Estudos Feministas, Floria nópolis, 14(3): 709-730, setembro-dezembro/2006 
da diferença dos sexos à diferença anatômica entre os sexos, e mais a inda a uma oposição binária descrita, em última instância, como presença ou ausência do pênis. Não seria possível repensarmos essa teoria à luz de uma outra formulação desse real, que não a reduzisse a o biná rio e a o a na tômic o? E, se a ssim for, nã o se toma possível pensar que uma mulher, enquanto sujeito passível de colocar-se como terceiro entre a criança e a mãe, de desejar e ser desejada por esta, de ver-se atribuída imaginariamente pela criança do objeto de desejo de sua mãe, que uma mulher, então, poderia ocuparo lugar da funçã o patema?

Supondo-se que isso não seja possível, que tenhamos de admitir que é, em última instância, a visão ou não pela criança do pênis que tomará possível uma inscrição da diferença sexual, e supondo-se também que esse terceiro marcado pela diferença a natômica com relação à mãe e a quem a crianç a possa a tribuir ima g ina riamente o fa lo não se apresente, será que nesse caso a função patema não se institui, o Nome-do-Pai é foracluído? Os filhos de mulheres homossexua is serã 0 , porta nto, necessa ria mente, psicótic os? A possibilida de que se apresenta aquia nós, caso recusemos esse determinismo que, aliás, parece não encontrar nenhuma relação com a realidade, assim como esse simplismo, que é critica do pelo próprio Dor, a o denunciar a tra nsforma ção da noção de fora c lusão do Nome-do-Pai em uma panacéia etiológic a à toda prova, a possibilidade que se apresenta a nós, nesse caso, é pensarmos a instituição da função patema pela fragmentação e multiplicação de seus agentes. Nesse caso, não seria mais necessário reunimos em uma mesma figura encamada a atribuição do falo e o real da diferença entre os sexos. Talvez devêssemos pensar que, com a desarticulação entre sexo e reprodução - seja pelasnovas práticas sociais, seja pelas novas práticas médicas - e com o despedaçamento tanto dasfamílias quanto da experiência reprodutiva, a figura do terceiro termo perde a sua unidade; ela se fragmenta e se multiplica. Não há ma is o Nome-do-Pai, e sim os nomes-dopai, ou a inda, como dirá Lacan, as père-versions, as várias versões e ao mesmo tempo perversões, no sentido de subversões, do pai.

A colocação em causa do aprisionamento da diferença dos sexos ao binarismo anatômico assim como da função paterna a uma unidade nos leva a formular, junto com Geneviève Delaisi de Parseval, que "podemos apostar sem muitos riscos que vai se abrir um campo de pesquisas inédito no domínio metapsicológico e a ntropológico, concemindo as diferentes declina ções do

${ }^{34}$ DELAISI DE PARSEVAL, 1999, $\mathrm{p}$. 231. 
${ }^{35}$ MOUG IN-LEMERLE, 2004, p. 2.

${ }^{36}$ MOUG IN-LEMERLE, 2004, p. 4

${ }^{37}$ MOUG IN-LEMERLE, 2004, p. 4.
Embora a teorização de J oël Dor sobre a noção de função paterna e do seu papel na estruturação do sujeito não o leve a opor-se de modo explíc ito à homo pa renta lida de, fomos conduzid os a explic ita ras vá rias dificuldades para se admitir essa situa ção a partir dessa teoriza ção. Se nos referimos a gora a Pierre Legendre, a utor cujos trabalhos têm insistindo bastante na importância da sustentação da diferença sexual e da transmissão da lei patema para a inscrição da criança no mundo simbólico, chegaremosa uma posição bem ma is c la ramente contrá ria à homoparentalidade. Com efeito, Legendre é o psicanalista que mais tem defendido publicamente de forma clara e feroz uma posição política contra a homoparentalidade.

Segundo Pierre Legendre, para se compreender a constituição do sujeito do desejo humano, é necessário abordarmos as articulações entre o Jurídico e o Psíquico. Isso porque é o direito quem insc reve o serhumano na ordem da filiação, segundo modalida des particula rese próprias a cada cultura. Como observa Régine Mougin-Lemerle, ao nos apresentar o pensamento de Legendre, é a lei quem nos diz filho ou filha daqueles que ela designa como nossos pais. Nós somos filhos da lei simbólica. Citando a a utora,

A criança humana não é o produto da came de seus progenitores, nem mesmo de seu desejo de filhos, ou de proezas biotecnológicas desenvolvidas nos procedimentos médicos de reprodução assistida. Ela é instituída como tal - filho de... ou filha de... - pelo Direito. O serhumano - a menosque se aceite uma 'concepção açougueira' e mortífera da filiação - é submetido ao primado do simbólic 0 , às leis genea lógic as. ${ }^{35}$

A inscrição da criança na ordem da filiação, condição para a sua instituição como serdeseja nte, se dá pela transmissão do sobrenome do pai, transmissão esta submetida a uma montagem jurídica bastante precisa e própria a cada cultura. Mesmo que as regras de pa rentesc 0 seja $m$ va riá veis segundo a s culturas, a interd ição do inc esto é universal. Enquanto transmissor de seu Nome, o pai representa, portanto, as leis da cidade e o interdito maior que as fundamenta: a proibição do incesto.

Como observa Mougin-Lemerle, "nenhuma sociedade deixa à fantasia, a o livre arbítrio dos pais ou do filho, a escolha de sua linhagem, a autorização de subverter as regras da filiação, a escolha do nome". ${ }^{36}$ As características jurídicas de indisponibilidade e de imutabilidade do nome, como lembra a autora, "dão à criança um espaço, uma moradia institucional, simbolizando um limite e portanto uma referência". ${ }^{37}$ É por 
${ }^{38}$ MOUG IN-LEMERLE, 2004, p. 5.

${ }^{39}$ LEGENDRE, 2004, p. 82. isso que, conclui ela, se, em nome dos interesses de alguns indivíduos, da ciência, ou de Estados demissionários de seu papel, manipularmos, sem tomar as devidas precauções, o quadro jurídico da nominação, se 'improvisarmos' muito a pressadamente nosso sistema jurídico relativo à linhagem humana, "nos a riscaremos a danos subjetivos considerá veis, nos a rriscaremos a desencadear crises de identidade [...], suscitando a ferocidade, a violência, a confusão".38

Segundo Pierre Legendre, é o Estado que, ao fomecer leis e jurisprudências, garante as montagens da filiação. É ele que, ao fomecer montagens instituciona is que ordenam e ultrapassam a relação dual ente os pais e os filhos, introduz um terceiro termo, ga rantindo os lugares estrutura is. A função de transmitir e submeter a criança (a ssim como seus pais) a essa montagem cabe, em primeiro luga r, a o juiz, e, em segundo lugar, a os próp rios pais.

Legendre nos oferece um exemplo, a seu ver, do fracasso dessa transmissão. Trata-se de um caso que ocorreu no Canadá em 1988, e o desc reveremos segundo os próprios termos do autor:

Uma criança de 14 anos vive com sua mãe descle 0 seu nascimento e não tem, segundo o texto do julgamento, nenhuma recordação do pai. O casamento dos pais foi dissolvido pelo divórcio e a guarda entregue à mãe. Esta obteve o direito, a partir da destituição do pai, da autoridade parental deste pai e a criança utiliza o nome da mãe. A história não pára aí. Esta mãe muda de sexo através de uma operação cirúrgica; ela, como diz o juiz, 'assume a aparência do sexo masculino', e logo obtém a mudança de nome. Tendo sido modificado, desta forma, o seu estado civil, esta mãe - ou melhor, este novo pai - solic ita um pedido de adoção de seu filho, a fim de lhe daruma certidão de nascimento conforme a nova identidade de seu genitor. Como os pareceres psic op siquiá tric os e dos a ssistentes soc ia is c onc luíram pela legitimidade da diligência, o tribunal lega lizou o pedido. Eu deveria dizer: a caixa registradora denominada tribunal. Percebo, nos considerandos da decisão, uma fómula dos especia lista s retoma da pelo juiz: 'Para esta criança, a mãe está morta'. ${ }^{39}$

Em seu comentário a respeito do caso e de sua solução, Legendre sustenta que a diferenciação, a via legal das identificações genealógicas e a sua ligação a um sistema institucional, elementos fundamentais para a estruturação da identidade da criança, estão aqui ausentes. A transformação da mãe em pai impede a diferenciação, a sua identific ação selvagem a o pai impede que a criança simbolize a idéia do pai. Isso porque a ex- 
${ }^{40}$ LEGENDRE, 2004, p. 85.

${ }^{41}$ LEGENDRE, 2004, p. 85. mãe, novo pai, a o invés de submeter-se à Lei, coloca-se enquanto Lei suprema para seu filho. Conseqüentemente, para essa criança, não haverá relação pensável com o Terceiro: a criança será sacrificada à mãe. E isso, conclui Legendre, com o aval de uma Justiça sem bússola.

Um pedido louco, isto é, desconhecedor de qualquer limite, e que por isso subverte qualquer montagem institucional de lugares, encontra-se com um juiz transformado em simples máquina registradora acolhedora de uma demanda sem limites. Eis como se organizam, segundo o psicanalista, as condições da própria a nulação da criança, as condições de sua destituição enquanto sujeito.

Como conclui o autor, esse exemplo é paradigmático do mal-estar contemporâneo diante da questão estrutural. Segundo suas palavras, "a lógica do Terc eiro, a lógic a da Referência está embaralha da. [...] nos to mamos todos mini-Esta dos; ou ainda [...] a triangula ção do sujeito [...] se resolve na fórmula 'Eu, mim e eu mesmo'". ${ }^{40}$ E o a utor continua:

Na prática, isso quer dizer o self-service nomativo. Éo triunfo dos idea is do sujeito-Rei, isto é, o sujeito que é para si próprio e para seu filho o Terceiro absoluto, a Referência. Nessas condições, não seriam mais teoric a mente pensá veis nem o Terc eiro, nem ta mpouco a Referência; não haveria ma is a função parental, nem um lugar para a criança... ${ }^{41}$

Eis com é gerada na contemporaneidade, a seu ver, a dessubjetivação das massas; eis como o nosso tempo produz um lote de sacrificados, de deficientes simbólicos vindo encarnar a debandada (suicídios, psicoses provoc a das antecipa da mente, a niquila mento subjetivo sob todas as sua s formas).

Esse pensamento catastrófico será duramente criticado por Michel Tort. Ao analisar a teoria de Pierre Legendre, o psicanalista critic ará, em primeiro lugar, o fa to de essa apresentar as estruturas de parentesco como origem do poder, ignorando que esse mesmo poder está na base dessas estruturas. Em segundo lugar, Legendre daria às regras de parentesco uma finalidade natural de preservação da espécie pela produção da vida e de suas diferenciações. Entretanto, observa Tort, é evidente que não há necessida de a lguma da instituição dessa s regras para que a vida se produza e se diferencie. Segundo suas próprias palavras, "assim como a antropologia não funda menta sua sa ná lises das estruturas de pa rentesc 0 nas perspectiva s supostas de 'conserva ção da espécie', a ssim também a psicanálise não faz do Édipo a simbolização 
42 TORT, 1992, p. 51-52.

${ }^{43}$ TORT, 1992, p. 53.

${ }^{44}$ TORT, 1992, p. 53.

${ }^{45}$ Lei que permite o casamento de homossexuais.

${ }^{46}$ Cita do por ROUDINESC O, 2003, p. 194.

${ }^{47}$ ROUDINESC O, 2003, p. 195. garantidora da perpetuação a dequada do phylum humano". ${ }^{42}$ Em terceiro lugar, ao ver de Tort, Legendre transferiria a simbolização inteiramente para a esfera jurídica, ignorando que, embora a 'genealogia' de que se trata na psicanálise, nos processos de geração, pressuponha as relações de parentesco, ela de modo algum se reduz a essas relações. Enfim, Legendre identific a ria as finalida des do direito e da psica nálise. Com efeito, o que ele sustenta é que a função das categorias jurídicas seria levar cada geração a reconhecer o Édipo. Dessa forma, a psicanálise seria alinhada à força em uma operação reacionária; a cena primária do direito seria "ou bem a genealogia impõe 'implacavelmente' sua ordem jurídica ao desejo inconsciente, ou é a loucura, a psicose!"; 43 e a verdade da psicanálise ver-se-ia reduzida a esta palavra de ordem: "fora do Pai, é a loucura!"44

Os termos nos qua is Pierre Legendre se pronuncia em uma entrevista publicada no jomal Le Monde em 2001 e citada por Elisabeth Roudinesco ilustram de modo bastante claro as conseqüências de sua teoria e noslevam a compreender que, para o autor, não apenas fora do pai, masta mbém fora da família tra dic ional papai-mamãecriança, é a loucura, a falta de razão. Eis os seus termos:

Pensem nas inic ia tivas toma das pelos homossexua is [...] 0 pequeno episódio do pac to de solidarieda de ${ }^{45}$ revela que esse Estado abdic ou de suas funções de garantia da razã o. [...] Instituir a homossexua lid a de com um sta tus familiar é colocar o princípio democrático a serviço da fantasia. Isso é fatal, na medida em que o direito, fundado no princípio genealógico, abre espaço para uma lógic a hedonista, herdeira do nazismo. ${ }^{46}$

O pensamento catastrófico de Legendre provocará uma formulação não menos catastrófica em Roudinesco. Em sua reação às palavras do psicanalista, Roudinesco formulará a seguinte questão: "Como não ver nessa fúria psicanalítica do fim do segundo milênio, qua ndo não o a núncio de sua agonia conceitual, pelo menos o sinal da incapacidade de seus representantes em pensar o movimento da história?"47

Se fazemos nossa a análise da autora quanto à agonia conceitual de um determinado pensamento que busca sustentar, na imutabilidade, as noções de Ordem simbólica, função patema e diferença dos sexos, não concordamos, entretanto, que essa agonia esteja referida ao pensamento psicanalítico como um todo. Como indicamos acima, em reação à cruzada homofóbica, a psicanálise viu surgir e se desenvolver em seu interior um movimento que, buscando refletir sobre suasbasesteóric as, 
vem efetuando uma reconsideração completa de suas certezas e trabalhando sobre novas e interessantes teorizações sobre as problemáticas da função patema, do Édipo e sobretudo da diferença sexual. Os psicanalistas Michel Tort, Geneviève Dela isi de Parseval e Sabine Prokhoris são três bons exemplos franceses desse movimento. Os psic a na lista s J oel Birman, Paulo Roberto Ceccarelli, Regina Néri, Silvia Alexim Nunes e Márcia Arán são representativos de uma das vertentes desse movimento no Brasil. Se, do ponto de vista político, a posição desses autores pode ser dita certa mente fa vorável à homopa renta lidade, do ponto de vista teórico, mais do que buscarem na teoria psicanalítica ferramentas já prontas para sustentar teoricamente suas posições políticas, esses autores vão buscar rever alguns conceitos psicanalíticos que vêm se transformando em certezas inabalá veis e a os quais recorrem incansa velmente aquele que, supostamente em nome da psicanálise, tem se colocado contra não a penas as filiações homossexua is como também as inúmeras mudanças a que os avanços tecnológicos e as evoluções soc ia is vêm nos conduzindo. Como já ind ic a do a c ima, são sobretudo as problemáticas de ordem simbólica, função paterna, diferença dos sexos e Édipo que serão por esses a utores questionadas, e, principalmente, no que conceme a os citados autores brasileiros, será a tra vés da noção freudiana de feminilidade que essas problemáticas serão trabalhadas. Vale observarque, em Freud, essa noção tem o sentido daquilo que o conduz já tardiamente à necessidade de rever toda a sua teoriza ção sobre o Édipo e a diferença dos sexos como também, a o mesmo tempo, significa, para o sujeito, o limite do analisá vel. Portanto, operacionalmente, a abordagem dessa noção problemática assim como a abordagem de uma série de problemáticas a través desta noção, antes de leva rem a certezas, permitem que o analista se defronte com o enigmático, com aquilo para o que ele não tem resposta, ou mais precisamente, com aquilo que o seu afazer tem por excelência relação. A nosso ver, não apenas cabe a nós, a nalistas, toma mos uma posição política favorável à homoparentalidade, o que só julgamos ser necessá rio em vista da virulência com a qual grande parte dos a nalistas tem se pronunciado contra essa situação - de fa to, como já indicou Michel Tort, esse tipo de debate nem mesmo deveria se dar, haja vista a psicanálise não ter nenhuma vocação para prescrever o que é certo e o que é errado, o que é patológico e o que é salutar no que conceme a práticas sociais e familiares -, mas precisamos, principalmente, encaramos o fato de que, em face dos avanços tecnológicos e sociais, algumas das grandes 
${ }^{48}$ DELAISI DE PARSEVAL, 1999

${ }^{49}$ DELAISI DE PARSEVAL, 1999

${ }^{50}$ Cita da por DELAISI DE PARSEVAL, 1999, p. 235 certezas psicanalíticas precisam ser urgentemente reconsideradas e que, no seu lugar, devemos permitir que falem o novo e as incertezas.

Como vimos a cima, a psic a na lista Geneviève Dela isi de Parseval, ${ }^{48}$ antes de apoiar-se nos fundamentos da psicanálise para emitir um parecer contrá rio à quilo que vem surgindo como novidade no campo da família e da filia ção, vê no a colhimento a esse novo uma possibilida de de surgimento de novas elaborações e formulações psicanalíticas a respeito do complexo de Édipo. Antes, portanto, de opor-se ao novo, a psicanálise pode ser positivamente provocada pelo novo. Vejamos agora em que sentido a psicanalista ind ic a que esse a colhimento do novo, mais do que estar referido à questão da ausência da diferença sexual, sendo esta tomada como um dado conhecido, implic a o a na lista, o a na lisa nd o e a soc iedade na construção de novos modelos de diferença sexual.

Em seu a rtigo sobre "a construçã o da pa rentalida de nos casa is de mesmo sexo", ${ }^{49}$ Dela isi de Parseval propõe a seguinte questã o: a inscrição na filia ção é nec essa ria mente liga da à heterossexualida de do casal proc riador ou o direito pode estabelecer uma filiação de um tipo inédito, ligando uma criança a dois pa is do mesmo sexo? E para responder a essa questã o, a autora irá em primeiro lugar recorrer a os trabalhos dos historia dores que demonstra m serum enga no considerar a família nuclear heterossexual e monogâmica como a família normal, suporte histórico, norma social e condição psicológica necessária para criar filhos. Ao contrário, o que vários trabalhos mostram é que ela é recente no Ocidente. E no momento em que essa forma de fa mília começa talveza deixarde ser a norma, a a utora considera que devemos levar em consideração uma definição ma is a mpla e ma is flexível da família. A definição proposta por Carol Levine, especialista americana de bioética, pa rece-lhe fornecer um exemplo interessante de um modo flexível e evolutivo de pensar. Eis a definição de família proposta por Levine:

Os membros de uma família são indivíduos que, por nascimento, a doção, casamento ou engajamento explíc ito, compartilha m laços pessoa is profundos e têm mutua mente o direito de recebere o deverde fomecer, na medida do possível, diversas formas de apoio, especia Imente em caso de necessidade. ${ }^{50}$

Em seguida, ela recorrerá à observação feita pela antropóloga Françoise Héritier que, a o ser consultada a respeito das novas questões coloca da s pelas reproduções assistidas, afirma: "é a união le gítima, tal como é definida portal ou tal sociedade, que dá legitimidade aos filhos e 
${ }^{51}$ Cita da por DELAISI DE PARSEVAL, 1999, p. 228.

52 DELAISI DE PARSEVAL, 1999, $p$. 230.

${ }^{53}$ DELAISI DE PARSEVAL, 1999, $p$. 231.

54 DELAISI DE PARSEVAL, 1999, $\mathrm{p}$. 242.

${ }^{55}$ BIRMAN, 2001, p. 33. c ria ipso facto sua afilia ção a um grupo". ${ }^{51}$ É, portanto, o reconhecimento pelo grupo do casal enquanto casal o princípio fundamental de inteligibilidade da filiação, qualquer que seja o sexo ou a idade dospais, ou mesmo o fato de que eles estejam vivos ou mortos no momento da concepção.

Esse reconhecimento estando a usente no caso dos casa is homossexua is, a questã o que Dela isi de Pa rseval irá se colocar e nos colocar é a seguinte: qual o papel do psicanalista ou que espécie de ajuda ele pode oferecera esses casais quando eles nos procuram? 0 papel do psicanalista nesse caso é, a seu ver, ajudar o casal "a construir laços em um registro simbólico, pelo estabelecimento de códigos sociais, de formas rituais compreensíveis por todos". ${ }^{52}$ É apenas a partir da construção desses laços, pelo esta belec imento de códigos socia is cla rose pela simbolização de pontos de referência, que a instituição de uma diferença entre os dois pais do mesmo sexo toma-se possível.

Assim, o risco de indiferenciação entre os dois pais, que a autora chama de problema 'incestual', "não resulta da situação homoparental enquanto tal, mas da recusa social em reconhecê-la, ou seja, de instituir papéis socia is distintos entre os dois pa is do mesmo sexo". ${ }^{53}$

É, portanto, apostando, em primeiro lugar, na possibilida de de a psica nálise, a partir do novo que acolhe em sua clínica, reformulara sua teoriza ção sobre o Édipo e a diferença sexual, e na capacidade de os sujeitos singulares e de a sociedade em geral construir novos modelos de diferença sexual que a psicanalista assume a sua posição diante da questão da homoparentalidade:

Nós estimamos [...] que a sociedade deveria, quando os ind ivíduos são leva dos a pedir uma a utorização ou uma ajuda para se tomarem pais, levar em conta um outro critério que não [...] aquele que faz da heterossexualidade uma garantia mínima e sine qua non de bom desenvolvimento da criança; e que pressupõe, a o contrário, que a sexualidade homossexual dos pais constituiria uma ameaça de parenta lida de 'perversa'. ${ }^{54}$

Como indica Joel Birman, "a constituição de um discurso sobre a diferença sexual é um acontecimento bastante recente na história do Ocidente, não obstante a na tura liza ção da quele disc urso" ${ }^{55}$ Até o final do século XVIII e início do século XX era o modelo do sexo único que dominava o imaginá rio sexual de nossa tra dição. Portanto, o paradigma da diferença sexual, a concepção do homem e da mulher como matrizes de naturezas plenamente diferenciadase absolutamente inconfundíveis, é fundante 
${ }^{56}$ A pesquisa empreendida na França por Sabine Prokhoris apresenta vários pontos em comum com aquela que Judith Butler, 2003, vem desenvolvendo nos Estados Unidos. Haja vista o nosso trabalho ter por objetivo aqui apresentar o cenário dos debates franceses sobre a homopa rentalidade, privilegiaremos expor o pensamento de Prokhoris. Julgamos, entretanto, pertinente nos referimos a qui a o trabalho de Butler, haja vista a importância dessa autora no cenário não apenasfrancês, mas ta $\mathrm{mbém}$ brasileiro, no que concerne às discussões sobre gênero e sexualidade. 57 PROKHORIS, 1999.

${ }^{58}$ PROKHORIS, 1999, p. 155.

59 PROKHORIS, 2000. e correlato da modernidade no Ocidente. Portanto, conc omita ntemente a o surg imento da modemida de, surge a oposição ontológic a homem/mulher, sendo essa oposição fundada em uma diferença de natureza. Como mostra Birman, essa suposta oposição natural é montada ao mesmo tempo para responder ao ideário igualitário da Revolução Francesa e para manter, a partir de uma fundamentação biológica, a supremacia do sexo masculino sobre o feminino.

Entre os inúmeros trabalhos que buscam explicitar que a diferença sexual não é senão o que Michel Foucault chamou de "disp ositivo de sexualida de", ou seja, um efeito normativo socialmente construído, e que buscam pensar em outros termos, fora do binômio homem-mulher, a diversidade sexual encontram-se os trabalhos que vem desenvolvendo a psicanalista Sabine Prokhoris. ${ }^{56}$

Em seu artigo sobre "a adoração das maiúsculas", Prokhoris ${ }^{57}$ indica que a Ordem ou Lei simbólica sobre a qual se fundamenta um certo discurso psicanalítico é, em última instância, a ordem sexual. É nos seguintes termos, irônicos, que ela se refere a tal discurso:

[...] é com uma Lei, imutável como indica a sua maiúscula, que teríamos que nos haver, e não mais com um simples dispositivo regulador, susceptível, por sua própria função, de modificações. Lei não tanto da natureza como da estrutura, instituindo o humano em sua humanidade verdadeira, um humano que deve ser estruturalmente homem ou mulher, a través da assunção da ordem que a sexualidade deve supostamente rea lizar. [...] 0 que supõe evidentemente que seja definido algo como uma identidade sexual, cujo destino se trataria de realizar, sem que seja permitido se desvencilhar das posições requeridas. Mas a 'identidade' a fortiori sexual é verdadeiramente um conceito psic a na lític 0 ? $^{58}$

A resposta da psicanalista a essa questão é cla ramente negativa. Como ela observa, se considerarmos como se dá o que a psicanálise descreve como as 'identific ações' masculinas e femininas em sua fluidez, consta ta remos que elas não cessam de questionar o belo ordenamento dessa repartição. Será essa constatação, talvez, que levará a a utora, no livro public a do um a no a pós a publicação desse artigo, ${ }^{59}$ a indicar que, a seu ver, a noção de diferença dos sexos tem sido tratada como um fetiche, a saber, algo supostamente intocável e inconto má vel, quando, de fa to, essa diferença não é senão uma 'formação do inconsciente'. Visto que toda formação do inconsciente provoca uma espécie de aprisionamento em um destino, cabe a p sicanalista desfazê-la. No lugar do 
${ }^{60}$ PRO KHORIS, 2001.

${ }^{61}$ FREUD, 1969[1920].
62 PROKHORIS, 2001, p. 9. Segundo a autora, esse é um limite da crítica empreendida por Michel Tort que se dirigiria à ordem simbólica, sem ating ir entretanto, a 'diferença dos sexos'. inválido, porém hegemônico, conceito de diferença dos sexos, Prokhoris propõe que se dê lugar à "vizinhança dos sexos", muito mais sintonizada com a arte das passagens própria da psicanálise.

Em um debate do qual participou em 2001 na Associação de Pais e Futuros Pa is Gays e Lésbicas, ${ }^{60}$ ela esclarece, de forma bastante límpida, os desenvolvimentos teóric os que a levam, politica mente, a sustentaruma posição francamente favorável à homoparentalidade. Segundo Prokhoris, a argumenta ção desfa vorá velà homopa renta lida de baseia-se em uma confusã o entre sexua ção e diferença dos sexos. É por essa razão que, a seu ver, é nec essá rio explicitar a diferença entre essas duas noções, diferença que o texto freudiano "Psicogênese de um caso de homossexualismo numa mulher"61 the ajuda a esclarecer: enquanto a noção de diferença dos sexos está articulada à idéia da existência a priori de uma identidade masculina e uma feminina, a 'sexuação' é algo construído pelo sujeito e não precisa necessariamente se dar sob a forma dessa diferença. Visto que, como mostra a psic ana lista, a diferença sexual não existe, quando, em nome da psicanálise, os homossexua is são acusados de negara diferença sexual ou de não oferecera uma criança criada porum casal homossexual as condições para o estabelecimento dessa diferença, eles são de fato acusados de negar algo que não existe. Por outro lado, o que é possível e necessá rio de se dar, tanto para os homossexua is quanto para os heterossexuais, é a sexuação, efeito e não princípio da vida amorosa.

Com efeito, o que os desenvolvimentos teóric os de Sabine Prokhoris indicam é que, segundo suas próprias palavras, "se não desconstruirmos a representação da sexua ção em termos de 'diferença dos sexos', não chegaremos nunca a o termo da crítica. Não chegaremos nunca a desmantelar verdadeira mente o que é dito como: 'não, pessoas de mesmo sexo não devem ser pais'". ${ }^{62}$

\section{Considerações fina is}

Haja vista a riqueza dos desenvolvimentos psicanalític os que vêm sendo trabalhados e das direções de pesquisa que têm se aberto nos últimos cinco anos em função das questões colocadas pelas reivindicações homossexua is a o direito à pa rentalidade, temos de consta ta $r$ que, a o menosa té o presente momento, no encontro dessas reivindicações com a psicanálise, as primeiras não se beneficiaram tanto desta última, quanto esta se beneficiou daquelas. Talvez esteja chegando o momento em que se tornou possível inverter essa relação, ou melhor, dar-lhe um mais justo equilíbrio. É o que, de nossa parte, esperamos. 
${ }^{63}$ PROKHORIS, 2001, p. 9.

${ }^{64}$ PRO KHORIS, 2001, p. 9.
Durante o debate na Associação de Pais e Futuros Pais Gays e Lésbicas, alguém se dirige a Sabine Prokhoris para dizer-lhe o quanto está perturbada com a sua a firmação de que a diferença sexual, que os homossexua is, em resposta às acusações que lhe são feitas, buscam incansavelmente provar que não negam, de fato não existe. A psicanalista, observa a moça, vai, nesse sentido, muito ma islonge do que ela própria e alguns homossexua is teria $\mathrm{m}$ ido. Sim, responde a psicana lista, e isso porque julga ser a sua crítica "importante também para liberar a heterossexualidade dos impasses nos quais esta se encontra", 63 visto que, "antes de a negação da diferença dos sexos ser o que nega a sexua-ção, é a representação da sexuação segundo o esquema da diferença dos sexos que nega a sexuação, e em todo caso outras versões da sexuação". 64

Eis como, ta lvez, os últimos desenvolvimentos teóric os da psicanálise estejam começando a reverter a favor das reivindicações homossexuais, a té mesmo no sentido de ind ic a ro qua nto os heterossexua is dependem, ta nto qua nto os homossexuais, da possibilidade de exercer a arte da passagem cujas portas têm sido ab ertas por aqueles que conduziram à coloc ação em causa da diferença dos sexos.

\section{Referências bibliográficas}

ARÁN, Marcia. "Os destinos da diferença sexual na cultura contemporânea". Revista Estudos Feministas, Florianópolis, v. 11, n. 2, p. 399-433, 2003.

"Políticas do desejo na atualidade: o reconhecimento social e jurídico do casal homossexual". Lugar Comum - Estudos de Mídia Cultura e Democracia, Rio de Janeiro, v. 21, p. 73-90, 2005.

BATEMAN, Simone. "La Responsa bilité medica le a ux frontières de l'a c tivité théra peutique: les cas de l'assista nce medicale a la procréation". In: IACUB, Marcela; JOUANNET, Pierre (Dir.). J uger la vie: les choix médicaux en matière de procréation. Paris: Editions La Decouvert, 2001. p. 111-126.

BIRMAN, Joel. Cartografias do feminino. Rio de Janeiro: Editora 34, 1999.

Gramáticas do erotismo: a feminilidade e as suas formas de subjetivação em psic a nálise. Rio de J a neiro: C ivilização Bra sileira, 2001.

BO RILO, Da niel "Fa nta smes des juristes vs Ra tio juris: la doxa des privatistes sur l'union entre personnes du même sexe". In: BORILO, Daniel; FASSIN, Eric; IACUB, Marcela (Orgs.). Au-delà du PaC S: L'expertise fa miliale à l'épreuve de I'homossexualité. Paris: PUF, 1999. p. 161-185. 
BORILO, Daniel; FASSIN, Eric; IACUB, Marcela (Orgs.). Audelà du PaCS: L'expertise familiale à l'épreuve de I'homossexualité. Pa ris: PUF, 1999.

BRAUNER, Maria Claudia "Novas tec nologias reprodutivase projeto parental: contribuição para o debate no direito brasileiro". J ornal Brasileiro de Reprodução Assistida, v. 8, n. 3, p. 7-14, maio/jun./jul. 2004.

BUTLER, J . Problemas de gênero: feminismo e subversão da identidade. Rio de Ja neiro: Civiliza ção bra sileira, 2003.

C HATEL, Marie-Magdeleine. Les Femmes et la médicine de l'enfantement. Paris: Alb in Michel, 1993.

CORRÊA, Marilena Vilella. Novas tec nologias reprodutivas: limites da biologia ou biologia sem limites? Rio de Janeiro: Eduerj, 2001.

COSTA, Jurandir F. A face e o verso: estudos sobre o homoerotismo II. São Paulo: Escuta, 1995.

COSTA, Rosely "Tecnologias reprodutivas e a tribuições de paternida de e ma temida de". In: GROSSI, Miria m; PO RTO, Rozeli; TAMANINI, Marlene (Orgs.). Novas tecnologias reprodutivas conceptivas: questões e desafios. Brasília: LetrasLivres, 2003. p. 69 -77.

DELAISI, Geneviève; VERDIER, Pierre. Enfant de personne. Paris: Éditions Odile J a cob, 1994.

DELAISI DE PARSEVAL, Geneviève "La construction de la parenta lité dans les couples de même sexe". In: BO RILO, Daniel; FASSIN, Eric; IAC UB, Marcela (Orgs.). Au-delà du PaCS: L'expertise familiale à l'épreuve de I'homossexualité. Paris: PUF, 1999. p. 225-244.

DINIZ, Débora; BUGLONE, Samantha (Eds.). Quem pode ter acesso às tecnologias reprodutivas? Diferentes perspectivas do direito brasileiro. Brasília: LetrasLivres, 2002.

DINIZ, Débora; GOMES COSTA, Rosely. "Infertilidade e infecundidade: acesso às novas tecnologias conceptivas". Artigo enviado para a 4a Jomada do Espa ç o Brasileiro de Estudos Psic a na lític os, rea liza da de 19 a 21 de maio de 2005, no Auditório do IBAM, Rio de Janeiro. Inédito.

DOR, Joël. O pai e sua função em psicanálise. Rio de Ja neiro: Jorge Zahar Editor, 1991.

FRAISSE, Geneviève. "Le jeu a poréptique des deux sexes". In: FEDIDA, Pierre ; LECOURT, Dominique (Dir.). La sexualité a-t-elle un avenir? Paris: PUF, 1999. p. 97-102.

FREUD, Sigmund. "Psicogênese de um caso de homossexualismo numa mulher". Edições Standard Brasileira das Obras Psicológic as Completas de Sigmund Freud. Rio de Janeiro: Imago, 1969[1920]. v. XVIII, p. 183-212. 
GOODY, Esther N. Parenthood and Social Reproduction. Cambridge: Cambridge University Press, 1982.

GROSS, Martine. Homoparentalités. État dês lieux. Issy les Moulineaux: ESF Éditeur, 2000.

GROSSI, Miriam P. "Gênero e parentesco: familias gays e lésbic as no Brasil". Cadernos Pagu, Campinas, v. 21, p. 261-280, 2003.

HÉRITIER-AUGÉ, Françoise. "La cuisse de Jupiter". L'Homme, n. 94, p. 5-22, 1985.

IACUB, Marcela. "Homopa rentalité et ordre proc réatif". In: BO RILO, Da niel; FASSIN, Eric; IAC UB, Marcela (Orgs.). Audelà du PaCS: L'expertise familiale à l'épreuve de I'homossexualité. Paris: PUF, 1999. p. 189-204.

LEG ENDRE, Pierre. "Poder genea ló g ico do Esta do". In: ALTOÉ, Sonia (Org.). Sujeito do direito, sujeito do desejo: direito e psicanálise. Rio de J a neiro: Revinter, 2004. p. 79-87.

MOUGIN-LEMERLE, Régine "Sujeito do direito, sujeito do desejo". In: ALTOÉ, Sonia (Org.). Sujeito do direito, sujeito do desejo: direito e psic a nálise. Rio de J a neiro: Revinter, 2004. p. 1-14

NERI, Regina. A psicanálise e o feminino: um horizonte da modernidade. Rio de Janeiro: Editora 34, 2005.

NUNES, Silvia A. O corpo do diabo entre a cruz e a caldeirinha: um estudo sobre a mulher, o masoquismo e a feminilidade em Freud. Rio de Janeiro: Editora 34, 2000.

PERELSO N, Simone. "As nova s forma s de filia çã o: c lona gem, reproduções a rtificia is, mono, multi e homoparentalidade". Revista Contemporânea, Public ação Eletrônica do Programa de Pós-Graduação em Comunic ação da Faculdade de Comunicação Social da UERJ, ano 1, n. 1, dez 2003. Disponível em: http ://www2. uerj.br/ fcs/contemporanea / conexclone.htm.

"O corpo face às novas formas de reprodução. Do mito a o resto: sobre clonese embriões congelados". Logos, Rio de Ja neiro, a no 11, n. 20, p. 116-133, 1. sem. 2004.

PRO KHORIS, Sabine. "L'a doration des majuscules". In: BO RILO, Daniel; FASSIN, Eric; IAC UB, Marcela (Orgs.). Audelà du PaCS: L'expertise familiale à l'épreuve de I'homossexualité. Paris: PUF, 1999. p. 145-159.

Le sexe prescrit. Paris: Aubier, 2000.

“La 'différence des sexes': quelle construction, pour quels enjeux?" In: Débathèmes, 2001. Disponível em: http ://www.france.q rd .o rg/a ssoc s/a pg l/d oc uments/ dt_200106.htm. Acesso em: 8 jan. 2006. 
RAMIREZSAPUCAIA, Magda lena. "'Pa ter semper incertus est', enquanto a mãe é certíssima: o fim de uma era". In: BEC KER, Paulo (Org.). Bioética no Brasil. Rio de Janeiro: Espaço e Tempo, 1999. p. 77-96.

ROUDINESC O, Elisabeth. A família em desordem. Rio de Janeiro: J orge Zahar, 2003.

STRATHERN, Marilyn. Reproducing the Future: Essays on Anthropology, Kinship and the New Reproductive Technologies. Manchester: Manchester University Press, 1992.

TAMANINI, Marlene. "Novas tec nologias reprodutivas conceptivas: bioética e controvérsia". Revista Estudos Feministas, Floria nópolis, v. 12, n. 1, p. 73-107, 2004.

TARNOVSKI, Flá vio Luiz. Pa is a ssumidos: a doção e paternidade homossexual no Brasil contemporâneo. 2002. Dissertação de Mestra do - Universida de Federal de Santa Catarina, Florianópolis.

TORT, Michel. Le désir froid: procréation artific ielle et crise des repères symboliques. Paris: La Découverte, 1992. 1999.

"Homophobies psychana lytiques". Le Monde, 15 oct

UZIEL, Anna Paula. "Conjugalidade, parentalidade e homossexualidade". Saúde, Sexo e Sociedade, Rio de Janeiro, ano X, n. 26 e 27, p. 36-41, 2002.

"Homossexualidade e parentalidade: ecos de conjugação". In: HEILBORN, Maria Luiza (Org.). Família e sexualidade. Rio de Janeiro: Editora da FGV, 2004. p. 87-117.

VACQUIN, Monette. "Vers la 'guérison' de l'espèce?" In: FERENC Z, Thomas (Dir.). Changer la vie? Paris: Éditions Complexe, 2001. p. 53-67.

[Recebido em abril de 2005 e aceito para publicação em fevereiro de 2006]

The Homosexual Parenthood: An Exposition of the Psychoanalytical Debate in the Contemporary French Scenario

Abstract: After situating homoparenthood within the context of the new social and medical practices concerning parenthood and reproduction, the article presents a scenario of the contemporary French debate on this issue. The thinking of five psychoa nalysts on this matter will be broached : J oël Dor and his theory about the role of the function of the father and about the a natomic difference between sexes in the structure process of the subject; Pierre Legendre and his articulation between the fields of law and the psych in the involvement of the human being in the order of parenthood; Mic hel Tort and his critic ism of the theories of that a uthor; and Genevieve Delaisi de Parseval and her proposal of a broader definition of the family. And, finally, Sabine Prokhoris, and her distinction between "sexuation" and "difference of the sexes". This presentation intends to dismantle the opposite arguments and demonstrates the legitimac $y$ of the rea soning favorable to homosexual parenthood.

Key Words: Homoparenthood; Reproduction; Parenthood. 